\title{
FRAGMENTOS POLÍTICOS
}

\author{
Jean-Jacques Rousseau \\ Tradução, Apresentação e notas de Rafael de Araújo e Viana Leite ${ }^{1}$ \\ Universidade Federal do Paraná (UFPR) \\ https://orcid.org/0000-0002-1676-6428
}

\section{Apresentação}

O terceiro Tomo das obras completas de Jean-Jacques Rousseau (Gallimard, 1964), conta com uma seção de textos organizados e anotados por Robert Derathé, classificados como Fragmentos políticos. Eles são divididos em dezesseis, a partir de uma organização cujo objetivo não é o de ser cronológica nem mesmo evolutiva. Note-se que Rousseau não foi o responsável por essa divisão nem pelos títulos sugeridos a cada fragmento. Sobre esses textos, eles possuem tamanho desigual e apresentam grande variedade temática. Em muitos casos, o leitor é apresentado a aspectos fundamentais do sistema filosófico de Rousseau. Trata-se de anotações, variantes de trechos encontrados em livros publicados ou passagens de obras nunca finalizadas. O objetivo dessa tradução é participar do esforço por apresentar aos interessados no pensamento rousseauniano traduções inéditas e relevantes. Para o momento, ofereço traduzidos quatro Fragmentos políticos de Rousseau, a saber, Das Leis, Economia e finanças, Da população e Da Pátria. ${ }^{2}$ Temas inquestionavelmente importantes para a reflexão política de Rousseau e que serão, além disso, tratados em mais de uma ocasião em suas obras.

\section{TRADUÇÃO}

\section{DAS LEIS}

Remontando à origem do direito político, descobre-se que antes de haver chefes houveram necessariamente leis. Foi preciso ao menos uma para estabelecer a confederação pública, e foi preciso uma segunda para estabelecer a forma de governo. ${ }^{3}$ Essas duas leis supõem muitas outras intermediárias, cuja mais solene e

\footnotetext{
${ }^{1}$ Doutorando em Filosofia pela Universidade Federal do Paraná (UFPR), Paraná - Brasil. Bolsista CAPES. Membro do Grupo de Estudos das Luzes (UFPR). Membro estudante do Grupo Interdisciplinar de Pesquisa Jean-Jacques Rousseau. Email: rafael_vianaleite@hotmail.com.

${ }^{2}$ ROUSSEAU, JEAN-JACQUES. Oeuvres complètes. Du Contrat social - Écrits politiques. Org. Bernard Gagnebin e Marcel Raymond. Tome III. Paris: Pleiade, 1964. A paginação dos fragmentos traduzidos é, respectivamente, pp. 491-500; pp. 525-526; pp. 527-528 e pp. 534-537.

${ }^{3}$ Lemos em nota, na Edição da Pleiade, que por 'confederação pública' deve-se entender associação política ou sociedade civil.
}

ROUSSEAU, Jean-Jacques. Fragmentos políticos. Tradução, apresentação e notas de Rafael de Araújo e Viana Leite. Griot : Revista de Filosofia, Amargosa, Bahia, v.16, n.2, p.423-434, dezembro/2017. 
mais sagrada foi aquela pela qual comprometeram-se à observação de todas as outras. Se as leis existem antes do governo elas são, portanto, independentes dele. $O$ governo ele mesmo depende das leis porque é unicamente delas que extrai sua autoridade e longe de ser delas o autor ou o mestre não é senão sua garantia, o administrador e, no máximo, o seu intérprete.

São essas capitulações que fazem o direito e a segurança dos soberanos, e ninguém é obrigado a obedecer aos magistrados senão em virtude das Leis fundamentais do estado, Leis as quais os próprios magistrados são obrigados a obedecer. ${ }^{4}$

Em todo sermão que um ministro ou outro oficial qualquer disponibiliza ao seu príncipe, deve-se subentender sempre essa cláusula: exceto as leis do Estado e a conveniência do Povo.

O que torna as leis tão sagradas, mesmo independentemente de sua própria autoridade, e tão preferíveis a simples atos da vontade? É, primeiramente, por elas emanarem de uma vontade geral sempre correta no que diz respeito aos particulares. É, ainda, por elas serem permanentes, e por sua duração anunciar a todos a sabedoria e a equidade com a qual foram ditadas.

Somos livres, ainda que submetidos pelas leis, e não quando obedecemos a um homem porque, nesse último caso, obedeço à vontade de outro, porém, obedecendo à Lei só obedeço à vontade pública que é tanto a minha quanto aquela de quem quer que seja. Além disso, um mestre pode permitir a alguém o que ele próibe a um outro. As leis, diferentemente, não fazendo nenhuma distinção, a condição de todos é igual e, por consequência, não há nem mestre nem servidor.

\section{Das Leis}

O único estudo que convém a um bom Povo é aquele das Leis. É preciso que ele medite sobre elas sem cessar para amá-las, para observá-las, mesmo para corrigilas com as precauções que um assunto dessa importância exige, quando a necessidade é urgente e verdadeira. Todo Estado em que há mais Leis do que a memória de cada cidadão pode reter é um Estado mal constituído, e todo homem que não saiba prontamente as leis de seu país é um mal cidadão. Assim, Licurgo não desejou senão escrever nos corações dos esparciatas.

\footnotetext{
4 No texto original há certa oscilação entre a grafia em maiúscula e minúscula de palavras como 'lei', ‘povo' e 'estado'. Mantive essa oscilação.
}

ROUSSEAU, Jean-Jacques. Fragmentos políticos. Tradução, apresentação e notas de Rafael de Araújo e Viana Leite. Griot : Revista de Filosofia, Amargosa, Bahia, v.16, n.2, p.423-434, dezembro/2017. 
Se me perguntassem qual é o mais vicioso de todos os Povos, responderia sem hesitar ser aquele cujas Leis são em maior número. A vontade de fazer bem supre tudo e aquele que sabe escutar a lei da sua consciência não tem muita precisão de outras, porém, a multidão de Leis anuncia duas coisas igualmente perigosas e que caminham quase sempre juntas, a saber, Leis ruins e sem vigor. Se a Lei fosse suficientemente clara ela não teria necessidade de incessantes novas interpretações ou de novas modificações, caso ela fosse suficientemente sábia. E se ela fosse amada e respeitada não veríamos essas funestas e odiosas contenções entre os cidadãos, para se esquivar dela, e do soberano, para mantê-la. Essas multidões terríveis de Éditos e de declarações que vemos emanar cotidianamente de certas cortes não fazem mais do que ensinar a todos que o Povo despreza com razão a vontade do seu soberano, e excitar a desprezá-la ainda mais ao ver que mesmo ele não sabe o que quer. $O$ primeiro preceito da Lei deve ser o de fazer com que se ame todos os outros. Porém, não é o ferro nem a chibata dos preceptores da corte que fazem com que ele seja observado. E, entretanto, sem ele, todos os outros de pouco servem, pois prega-se inutilmente àquele que não tem nenhum desejo de agir bem.

Apliquemos esses princípios a todas as nossas Leis, nos será fácil de assinalar o grau de estima que se deve àqueles responsáveis por redigi-las e àqueles para quem elas foram feitas. Por exemplo, a primeira reflexão que se apresenta quando consideramos a grande coletânea de Justiniano é a de que essa obra imensa foi feita para um grande povo, isto é, para homens incapazes de amar suas leis, por consequência, de observá-las, e mesmo de conhecê-las. De sorte que, desejando tudo prever, Justiniano fez uma obra inútil.

Que se preste atenção na multidão enorme dessas Leis ou nas perpétuas discussões de interesse sobre as quais elas gravitam quase unicamente, ou às diversas interpretações em relação às quais, aparentemente, teve-se o cuidado de torná-las suscetíveis, reconhece-se aí facilmente a avareza que as ditou. Que Triboniano e Teodora as tenham vendido àquele que pagou mais, não tenho necessidade de que Procópio disso me instrua. Procópio pode ter sido um caluniador, porém, um testemunho mais forte do que o seu é aquele fornecido por essas próprias Leis e pelos costumes da Corte de onde elas foram compiladas.

Um lacedemônio, interrogado por um estrangeiro sobre a pena infligida aos parricidas por Licurgo, lhe respondeu que obrigavam o culpado a dar de comer a um boi capaz de beber água do rio Eurotas do cume do monte Taigeto. Como, gritou o estrangeiro, seria possível encontrar um boi como esse? Mais facilmente, respondeu o lacedemônio, do que um parricida em Esparta. O terror pode conter os celerados, porém, a corrupção de um povo nunca se começa pelos grandes crimes, e é para prevenir esses inícios que é preciso empregar toda a força das Leis.

Eis o princípio em relação ao qual é preciso julgar do que podem as leis, não somente para aterrorizar o vício, mas também para encorajar a virtude. Sei que o primeiro prêmio das boas ações é tê-las realizado, porém, os homens só conhecem 
esse prazer depois de tê-lo provado, e são necessários motivos mais sensíveis para lhes dar o primeiro hábito de bem agir. Esses motivos são as recompensas bem escolhidas e ainda melhor distribuídas. Sem o quê, longe de honrar a virtude, elas não farão mais do que excitar a hipocrisia e nutrir a avareza. Essa escolha e essa distribuição são as obras-primas do legislador.

Um preceptor ruim só sabe usar da chibata. Um ministro ruim só sabe mandar enforcar ou enviar para a prisão. Assim, nossos políticos, que só acreditam realizáveis as pequenas coisas das quais são capazes, não terão escrúpulos em adotar essas máximas, e é até melhor para nós, pois se eles admitissem a utilidade das recompensas não imaginariam outras a não ser dinheiro, pensões e gratificações. Eles estabeleceriam rapidamente novos impostos, cuja distribuição se daria em pequenas porções, para essas tropas de escravos e de patifes que os cercam, e colocariam o resto em seus bolsos. Eis tudo o que o povo ganharia com isso.

Um autor moderno capaz sabe instruir pelas coisas que diz e por aquelas que ele faz pensar, nos ensina o seguinte: "tudo o que a lei propõe por recompensa torna-se, com efeito, uma"5. Não era, portanto, mais difícil aos legisladores excitar as boas ações do que impedir as ruins. Entretanto, quase todos eles se limitaram a assegurar a punição pública e a regrar os conflitos de interesse entre os particulares, dois objetivos que não deveriam estar a encargo da Legislação em um Estado bem constituído.

As Leis que falam incessantemente em punir e jamais em recompensar são mais próprias a conter celerados do que a formar pessoas honestas. Enquanto as Leis limitarem-se às ações, sem nada dizer à vontade, elas serão sempre mal observadas, porque ainda que sejam concebidas com alguma sabedoria, a intenção ruim oferece sempre luzes suficientes para ensinar a esquivar-se delas.

Algo em relação ao qual não podemos admirar demasiadamente é que entre os primeiros romanos a única punição aplicada pelas Leis das 12 tábuas contra os maiores criminosos era estar em horror perante todos, sacer estod. Pode-se conceber melhor o quanto esse povo era virtuoso somente imaginando que o ódio ou a estima pública era para eles uma pena ou uma recompensa distribuída pela Lei.

\footnotetext{
${ }^{5}$ Em nota, na Edição da Pleiade, lemos que muito provavelmente, apesar de não ser uma citação exata, Rousseau tinha em mente o Espírito das leis, de Montesquieu (Livro VI, Cap. IX).

ROUSSEAU, Jean-Jacques. Fragmentos políticos. Tradução, apresentação e notas de Rafael de Araújo e Viana Leite. Griot : Revista de Filosofia, Amargosa, Bahia, v.16, n.2, p.423-434, dezembro/2017. 
De sorte que em um Estado sabiamente ordenado ${ }^{6}$ a Lei poderia dizer como a sacerdotisa Teano: Não sou ministra dos deuses para detestar e reprovar, mas para louvar e abençoar.

A história antiga é recheada de provas do cuidado do povo para com os costumes dos particulares, e essa atenção mesmo perfazia a pena ou a recompensa mais sensível.

Os legisladores sanguinários que, a exemplo dos Draco, sabem somente ameaçar e punir se parecem com esses preceptores ruins que ensinam as crianças unicamente com a chibata na mão.

As Leis e o exercício da justiça não são entre nós senão a arte de colocar o grande e o rico ao abrigo das justas represálias do pobre.

Eles fazem valer todo o rigor das leis para vingar os erros dos outros para com eles, e esquivam-se delas facilmente em tudo o que fazem aos outros.

Tendo as leis se multiplicado a tal ponto que ninguém pôde observá-las todas, e uma infinidade de coisas naturalmente inocentes tendo sido proibidas ao povo pelos privilégios exclusivos que os poderosos se atribuíram, o pouco de escrúpulo que fez com que algumas leis fossem enfrentadas estendeu-se a todas as outras. É assim que as leis sumptuárias, modificadas pela diversidade de classes, fomentaram o luxo no lugar de extingui-lo. É assim que alguém que sempre considerou o roubo como algo horrível, e que foi pego pescando sem muito escrúpulo em local proibido, começou a contrabandear, e terminou assaltando nas estradas.

Jamais o homem honesto renunciará à honra, jamais o patife fará algo por amor pela lei.

Ouso afirmar que as Leis contra os duelos são produto da ignorância e de um espírito pequeno. Desejando remediar os abusos atuais, aqueles que as impuseram não souberam enxergar mais longe e ver o golpe mortal que eles infligiam à autoridade legislativa. É algo terrível obrigar os Povos a colocar a lei em oposição à honra, e ter de optar entre uma e outra.

${ }^{6}$ No original em francês, 'policié', que no infinitivo torna-se 'police'. No francês do século XVIII, diz respeito à regramentos de uma sociedade, ordem, não importando se estamos falando de monarquia ou república.

ROUSSEAU, Jean-Jacques. Fragmentos políticos. Tradução, apresentação e notas de Rafael de Araújo e Viana Leite. Griot : Revista de Filosofia, Amargosa, Bahia, v.16, n.2, p.423-434, dezembro/2017. 
É preciso notar que quando esses preconceitos bárbaros se estabeleceram eles não tinham o mesmo inconveniente de hoje em dia, porque naquela época a lei do Príncipe e aquela da honra falavam exatamente a mesma língua.

Pelas leis romanas as heranças deixadas para pessoas indignas eram levadas ao fisco. Hoje em dia, por mais ávidos que os Príncipes sejam, lhes é impossível aplicarem essa Lei, pois nesta época feliz não se encontra mais ninguém indigno de receber uma herança. L. I. de jure fisc.

Econômicos p. 6 .

Em relação aos Povos, uma vez corrompidos, é bem difícil distinguir o que deveria ser feito para torná-los melhores. Ignoro quais leis poderiam fazer esse milagre, porém, o que sei muito bem é que tudo está perdido sem recurso quando é preciso recorrer uma vez à potência e ao cadafalso.

[Dos judeus]

Nos tempos antigos, seja pelo fato de que os homens mais próximos de sua origem não tinham nada para enxergar além dela, seja porque naquele tempo as tradições menos disseminadas perecem em um esquecimento imediato, não se vê mais, como outrora, os povos celebrando sua condição de autóctones, aborígenes, filhos da terra ou do cantão onde eles se estabeleceram. As frequentes revoluções do gênero humano o transportaram de tal maneira, confundindo as nações, que talvez, com exceção da África, não reste nenhuma sobre a Terra que possa celebrar o fato de ser originária do país do qual ela tem posse. Nessa confusão da espécie humana, tantas raças diferentes habitaram sucessivamente os mesmos lugares e se sucederam ou se misturaram que essas raças não se distinguem mais, e os diversos nomes dos povos não são mais do que o nome dos lugares onde eles habitam. Se acaso restam em alguns deles traços de filiação, como entre os Parsis e Cimbros, eles não se encontram mais em seu antigo território nem se pode mais dizer que eles componham um corpo de nação? .

Entretanto, um espetáculo surpreendente e verdadeiramente único é ver um povo expatriado, não tendo mais nem lugar nem terra depois de dois mil anos, um povo alterado, sobrecarregado, misturado com estrangeiros desde tempos mais longínquos ainda, não tendo mais talvez um único filho das primeiras raças, um povo esparso, disperso sobre a terra, em estado de sujeição, perseguido, desprezado por todas as nações conservar, entretanto, seus costumes, leis, hábitos, seu amor

\footnotetext{
${ }^{7}$ Parsis: são conhecidos como seguidores do zoroastrismo, se encontram atualmente na região do Irã e Índia. Cimbros: um dos povos germânicos que lutaram contra os romanos entre 113-101 a. C., sob o comando do rei Boiorix.
}

ROUSSEAU, Jean-Jacques. Fragmentos políticos. Tradução, apresentação e notas de Rafael de Araújo e Viana Leite. Griot : Revista de Filosofia, Amargosa, Bahia, v.16, n.2, p.423-434, dezembro/2017. 
patriótico e sua primeira união social quando toda ligação parecia rompida. Os judeus nos oferecem esse espetáculo surpreendente. As Leis de Sólon, de Numa e de Licurgo estão mortas. Aquelas de Moisés, bem mais antigas, ainda estão vivas. Atenas, Esparta e Roma pereceram e não deixaram mais filhos sobre a terra. Sião destruída não perdeu os seus, eles se conservam, se multiplicam, se estendem por todo o mundo e se reconhecem sempre. Misturam-se a todos os povos e não se confundem jamais com eles. Não têm mais chefes e continuam sendo um povo. Não têm mais pátria e continuam sendo cidadãos.

Qual deve ser a força de uma legislação capaz de realizar tamanhos prodígios, capaz de afrontar as conquistas, as dispersões, as revoluções e os séculos. Capaz de sobreviver aos costumes, às leis e ao império de todas as nações. Que promete, enfim, pelas provações pelas quais passou defender-se diante de todas as outras, de vencer as vicissitudes das coisas humanas e de durar tanto quanto o mundo?

De todos os sistemas de legislação que nos são conhecidos uns são seres de razão, cuja própria possibilidade é disputada, outros duraram apenas alguns séculos, outros ainda não fizeram jamais um estado bem constituído. Nenhum, exceto o judaico, enfrentou todas as provações e sempre resistiu. O judeu e o cristão concordam ao reconhecerem que nisso há o dedo de Deus. Segundo uns, Ele mantém sua nação, e em acordo com os outros a castiga. Contudo, todo homem, quem quer que ele seja, deve reconhecer nisso uma maravilha única, cujas causas divinas ou humanas merecem certamente o estudo e a admiração dos sábios preferencialmente a tudo o que a Grécia e Roma nos oferecem de admirável no que diz respeito às instituições políticas e aos estabelecimentos humanos.

Fiz um povo e não pude fazer homens.

Que fazes entre nós, ó hebreu, vejo-te com prazer, mas como podes estar contente, tu, que nós desprezávamos tão fortemente, por qual motivo não ficastes entre os seus.

Engana-te, estou entre os meus. Vivi sozinho sobre a terra, no seio de um povo numeroso estava só. Licurgo, Sólon e Numa são meus irmãos. Venho reunir-me com minha família. Venho gozar, enfim, da doçura que é conversar com meus semelhantes, de falar e de ser ouvido. É entre vossas almas ilustres que venho, enfim, desfrutar de mim mesmo.

tu mudastes bastante de tom, de sentimentos e de ideias...

\section{ECONOMIA E FINANÇAS}


Dessa máxima, caso seja verdadeira, deduz-se consequentemente esta daqui: em tudo aquilo que depende da indústria humana, deve-se proscrever com zelo toda máquina e toda invenção que possa abreviar o trabalho, poupar a mão-de-obra e produzir o mesmo efeito com menos dificuldade.

Raciocinando de maneira bem consequente, deveríamos nos aplicar a dar pouco tempo de vida útil e de solidez às obras da indústria, e a torná-las o mais perecível quanto for possível, e a considerar como verdadeiras vantagens os incêndios, os naufrágios e todos os outros prejuízos responsáveis pela desolação dos homens.

Se alguém encontrasse algum meio de tornar a labuta mais fácil e de poupar o número de bois que nela são empregados, resultaria dessa invenção, necessariamente, uma diminuição do preço do trigo e um aumento do preço da carne bovina. Resta saber se essa engenhosidade seria tão útil aos pobres como ela seria prejudicial aos doentes, em maior necessidade de caldo do que de pão.

Em geral, é preciso observar que se a mão-de-obra multiplicada nas artes faz subsistir um grande número de homens ela torna, ao mesmo tempo, mais difícil a subsistência de todo povo pelo encarecimento dos gêneros alimentícios, resultado que é necessário.

Confesso que o dinheiro torna as trocas mais cômodas, porém, fazei melhor: torne as trocas pouco necessárias, fazei com que cada um, tanto quanto se possa, seja suficiente a si mesmo.

É privação de ferro que fez os americanos negligenciarem, depois esquecerem a navegação.

Os impostos são um tipo de renda que, por sua natureza, fundando-se em grande parte nas mãos que o recolhem, empobrecem o povo sem enriquecer a poupança e que, por consequência, faz sempre mais mal do que bem.

\section{8}

Após ter durante muito tempo se nutrido da bolsa dos ricos, a partir de empréstimos, e daquela dos pobres, por meio de impostos, será preciso necessariamente que a Inglaterra termine por declarar falência por esta única razão: ela só paga seus empréstimos pela cobrança de impostos.

ROUSSEAU, Jean-Jacques. Fragmentos políticos. Tradução, apresentação e notas de Rafael de Araújo e Viana Leite. Griot : Revista de Filosofia, Amargosa, Bahia, v.16, n.2, p.423-434, dezembro/2017. 


\section{DA POPULAÇ̃̃̃O}

1

Tenho apenas mais uma palavra a dizer antes de terminar esse artigo. Toda Economia geral se liga a uma finalidade última que é o efeito e a prova de uma boa administração. Essa finalidade, relativa ao bem geral da espécie humana, é a multiplicação do povo, consequência infalível de sua prosperidade. Desejais saber se um Estado é bem ou mal governado, examineis se o número de habitantes aumenta ou diminui. Todas coisas iguais, além disso, é evidente que o país responsável por, guardadas as proporções, alimentar e conservar o maior número de habitantes é aquele onde eles se encontram em melhor situação, e julga-se com razão o zelo do pastor em relação ao crescimento dos rebanhos.

Então, o Estado será o mais rico possível, pois ele terá em abundância a mercadoria mais preciosa, a saber, homens, e os homens que terá, ele os terá inteiramente.

Dessa experiência (que morrem mais homens nas grandes cidades e que há mais nascimentos no campo), é preciso concluir de duas coisas uma: ou que os habitantes do campo se multiplicam continuamente mais, a despeito de todos aqueles que são absorvidos incessantemente pela cidade, e as terras ficam permanentemente povoadas de modo igual, ou que o ambiente do campo em que há mais nascimentos é mais favorável para a população do que a cidade, onde há mais mortes.

Se o número de nascimentos é igual ao de mortes nos campos, e que o número de mortos ultrapassa comumente o número de nascimentos nas cidades, o despovoamento sucessivo é manifesto.

E o que importa para a sociedade que haja menos falecimento por assassinatos se o Estado é responsável por matá-los antes do seu nascimento, tornando as crianças onerosas aos pais.

Paris 1758

Mortos 19.202

Batismos 19.148

Casamentos 4.342

Crianças abandonadas 5.082

ROUSSEAU, Jean-Jacques. Fragmentos políticos. Tradução, apresentação e notas de Rafael de Araújo e Viana Leite. Griot : Revista de Filosofia, Amargosa, Bahia, v.16, n.2, p.423-434, dezembro/2017. 


\section{DA PÁTRIA}

A Terra em que habitamos é a mãe e nutridora de todos os homens, ela é a pátria do gênero humano. Entretanto, nenhum sentimento particular nos liga a ela. Se nós todos pudéssemos ser transportados para outro planeta, e viver nele mais agradavelmente, quem de nós iria ficar saudoso em relação a este daqui? Não se passa a mesma coisa no que diz respeito à afecção que nos liga ao nosso país natal, à pátria propriamente dita. Essa afecção varia tanto quanto os climas, os governos e as maneiras de viver. Uns, tendo nascido em um bom país, se esquecem dele sem dificuldade para viver em um país ruim. Outros, gozando de bem-estar em uma terra, lastimam incessantemente sua triste morada e suspiram com a lembrança de suas areias e dos seus rochedos. Para os primeiros, a pátria é todo lugar onde nos sentimos bem. Para os segundos, só estamos bem em nossa pátria. De onde vem uma tal oposição? Talvez por empregarem termos diferentes para dizer a mesma coisa, e que essa palavra, 'pátria', não tem o mesmo sentido em ambos os casos.

Essa ideia, que se apresentava desde muito tempo ao meu espírito de maneira obscura e confusa, por coincidência foi esclarecida e se desenvolveu quando dela eu pouco me ocupava. Lendo um dia o livro do Abade Dubos sobre a poesia e sobre a pintura deparei-me com uma passagem que me chamou atenção:

Conhecemos hoje povos cujo caráter, tal qual descrito pelos escritores antigos, referindo-se aos seus ancestrais, não mais lhes convêm atualmente. Os romanos não se parecem mais aos antigos romanos, tão famosos pelas suas virtudes militares. ${ }^{8}$

Diante dessas palavras, interrompo minha leitura, pergunto-me se é verdade que os romanos de hoje em dia sejam os compatriotas daqueles de outrora. Imagino com indignação:

Sacerdotes venturosos pisando com pé tranquilo

As tumbas dos Catão e as cinzas de Emílio. ${ }^{9}$

Procuro o que essas duas espécies de homens podem ter em comum sobre o mesmo solo. Aprofundo-me nas meditações que esse tema me apresenta, o livro escapa-me das mãos. As reflexões nascem às multidões e apagam-se sucessivamente com a mesma facilidade, sugerindo-me, enfim, que eu lance sobre o papel aquelas que teria conseguido reter. É essa coletânea informe e mal ordenada que será lida.

\footnotetext{
${ }^{8}$ Rousseau cita, não literalmente, uma passagem do livro do Abade Dubos, Réflexions critiques sur la poésie et sur la peinture, publivado pela primeira vez em 1719. A citação de Rousseau é baseada no Tomo II, seção XVI.

9 Trata-se de Paulo Emílio, cônsul romano morto na batalhe de Cannes.

ROUSSEAU, Jean-Jacques. Fragmentos políticos. Tradução, apresentação e notas de Rafael de Araújo e Viana Leite. Griot : Revista de Filosofia, Amargosa, Bahia, v.16, n.2, p.423-434, dezembro/2017. 
Para conhecer como os homens podem ser compatriotas é preciso saber o que é a pátria e por qual espécie de ligação ela une as pessoas. Pesquisa que não pode ser feita a não ser remontando às primeiras ligações do homem em geral.

Estimamos as coisas por meio de nossos apetites, as pessoas, pelas nossas afecções, e tanto em um caso quanto no outro pelo hábito. Não vejo nenhum outro tipo de ligação que possa conectar algum homem a certo lugar preferivelmente a um outro. Ora, sua constituição é tal que seus apetites nascem de suas necessidades e produzem seus hábitos. Para que os homens se conservem, individualmente ou tomados com espécie, é preciso que seus apetites naturais sejam satisfeitos, e dos seus apetites diariamente satisfeitos nascem os hábitos convenientes à sua conservação. De onde se seguiria que, por um efeito causado pelo amor por eles mesmos, todos os povos estando igualmente ligados aos objetos de seus apetites e de seus hábitos - que também são os instrumentos de sua conservação -, os homens deveriam ter a mesma ligação para com o solo que os nutre desde o seu nascimento, o único que oferece aos seus sentidos tais objetos. Caso houvesse alguma diferença, seria proporcional à maior ou menor facilidade para alcançar esses mesmos objetos, e aqueles que encontrassem mais dificilmente o necessário, deveriam amar menos o seu país, o que não está em acordo com o que foi dito anteriormente. Aquilo que se ama em seu país, o que se chama propriamente de pátria não é, portanto, o que se liga aos nossos apetites e aos hábitos que deles nascem, não é simplesmente o lugar, não são simplesmente as coisas, o objeto desse amor está mais próximo de nós.

Se os cidadãos extraem dela tudo o que pode dar valor à sua própria existência - sábias leis, costumes simples, o necessário, a paz, a liberdade e a estima pelos outros povos -, seu zelo será inflamado por uma mãe assim terna. Não conhecerão outra vida senão a que decorre dela, nem verdadeira felicidade que não seja engajar-se de modo a servi-la, e eles verão como parte de suas benfeitorias a honra de ter vertido seu sangue em defesa dela quando foi necessário.

E em acordo com a definição que dei de virtude, o amor pela pátria leva a ela necessariamente, porque desejamos de bom grado o que desejam aqueles amados por nós.

$\mathrm{O}$ amor pela humanidade fornece muitas virtudes, como a doçura, a equidade, a moderação, a caridade, a indulgência, porém, ele não inspira a coragem nem a firmeza, etc. E não lhe fornece a energia que elas recebem do amor pela pátria, capaz de elevá-las até o heroísmo.

Ao que parece, pelos diversos traços da história romana e, ademais, por aquela de Atílio Régulo, os romanos que caíam em mãos inimigas se consideravam como despojados do direito de cidadania e naturalizados, por assim dizer, em meio

ROUSSEAU, Jean-Jacques. Fragmentos políticos. Tradução, apresentação e notas de Rafael de Araújo e Viana Leite. Griot : Revista de Filosofia, Amargosa, Bahia, v.16, n.2, p.423-434, dezembro/2017. 
àqueles que lhes detinham como prisioneiros. Porém, essa máxima absurda encontrava-se somente em sua opinião, e não se percebia nenhuma influência dela na conduta desses homens virtuosos. $O$ próprio Régulo, que se considerava cartaginês, e recusara tomar lugar no senado de Roma, falava de tal modo contra os interesses de sua nova pátria e contra as instruções de seus senhores que, se é verdade que ele foi obrigado a lhes ser fiel e obedecer às suas ordens, a mais sublime das ações humanas seria tão somente o crime de um traidor. Seria preciso, para agir com equidade, aprovar o terrível suplício que os ferozes cartagineses lhe impuseram em punição por sua desobediência. ${ }^{10}$

Autor(a) para correspondência: Rafael de Araújo e Viana Leite, Universidade Federal do Paraná, Rua XV de Novembro, 1299 - Centro, CEP 80060-000, Curitiba - PR, Brasil. rafael_vianaleite@hotmail.com

10 Marco Atílio Régulo (299 a.C- ?), cônsul romano, símbolo de resistência heroica. Não se sabe ao certo se a história mencionada por Rousseau é verídica, contudo, conta-se que, feito prisioneiro entre os cartagineses, Régulo foi levado a Roma, enquanto escravo, na companhia de embaixadores para negociar a paz ou uma troca de prisioneiros. Caso não tivesse sucesso em negociar a paz, seria executado na volta a Cartago. Inicialmente, ele se recusou a entrar na cidade como prisioneirolescravo. Após ser forçado a entrar, recusou-se a tomar assento no senado romano e, mais do que isso, se colocou a incentivar os romanos a não aceitar a paz ou a troca de prisioneiros. Teria ainda estimulado o senado romano a tentar um último esforço contra o inimigo, pois, segundo ele, Cartago não resistiria por muito mais tempo. Apesar da invectivas de amigos, ele não aceitou permanecer em Roma e, cumprindo sua palavra, retornou para Cartago, onde morreu depois de ter sido exposto a tortura.

ROUSSEAU, Jean-Jacques. Fragmentos políticos. Tradução, apresentação e notas de Rafael de Araújo e Viana Leite. Griot : Revista de Filosofia, Amargosa, Bahia, v.16, n.2, p.423-434, dezembro/2017. 